for example, are $30 \%$ of district health authorities not expecting to meet the target date of 1993 to complete their initial call? Why are $46 \%$ of laboratories not undertaking the full recommended quality control, ${ }^{78}$ and, most critically, why have four laboratories with no quality control been permitted to continue screening at all?

Both the National Association of Health Authorities survey ${ }^{4}$ and Elkind $e t a l^{5}$ have shown that the workload being put on laboratories is becoming a serious problem - reflecting both inadequate funding and a lack of trained staff. It seems that NHS screeners are being attracted to the private sector by its higher salaries - and private practice is then being fuelled by NHS inadequacies. In a timely study Raffle et al (p 907) (who have experienced staff shortages) have audited workload rates and practices in Avon. ${ }^{9}$ A recall interval of three years has substantial medical support, ${ }^{10}$ and the audit by Elkind et al showed that it was operating in full or partially in half of all NHS districts.

The Avon study, however, shows that districts still struggling with a five year interval are invariably handicapped by numerous inappropriate opportunistic smears. Avon's successful policy of returning such smears unprocessed to the taker has proved successful and deserves widespread introduction. Their findings with respect to follow up smears, however, signal danger. Once they have implemented national follow up recommendations, ${ }^{11}{ }^{12}$ the authors' projections suggest that by 1993 half their present capacity will be required for this purpose. The message is clear: priority should be given to the investigation and treatment of severe rather than minor cytological abnormalities. Such a policy would improve cost effectiveness by conserving scarce laboratory and colposcopy resources and improve screening specificity. To date, there has been a preoccupation with programme sensitivity because of the emotive response to false negative results. It is now essential to redress the balance and give more consideration to the adverse effects of overdiagnosis and overtreatment.

The 1988 circular should by now have led to the NHS having a successful cervical screening programme. Sadly, however, after a promising start, many district health authorities have sought economic refuge in the "guideline" nature of the circular. The word guideline has been seen as permission to interpret widely and thereby avoid expenditure on all but the most sensitive issues.

The remedy is plain. The circular requires departmental enforcement to ensure appropriate funding - especially in the present climate of white paper flexibility.

At the moment each district cervical screening programme works in isolation, and this will not be changed by the implementation of the circular-nor has it been helped by the abandonment of the departmental committee on gynaecological cytology. Current problems in general practice are further evidence of inadequate central coordination and advice. It is wrong, for example, that some work conforming to the circular does not qualify for payment under the new contract. The NHS cervical screening programme requires leadership, integration, and standardisation in all its aspects, including management, clinical issues, information systems, quality assurance, development, education, training, and research. The Faculty of Community Medicine must be congratulated for initiating the national coordinating network with these objectives. ${ }^{13}$ As with the circular, however, the national coordinating network could be ineffective if not given departmental support and "bite" to guarantee adequate resources.

Consultant Histopathologist/Cytopathologist,

DAVID SLATER

Rotherham District Hospital,

Rotherham S60 2UD
1 Chamberlain J. Failure of the cervical cytology screening programme. Br Med $\mathcal{f}$ 1984;289:853-4 2 Anonymous. Cancer of the cervix: death by incompetence [Editorial]. Lancet 1985;ii:363-2.

Department of Health and Social Security, Health Services Management. Cervical cancer screening. London: Department of Health and Social Security, 1988. (HC (88) 1.)

4 National Association of Health Authorities. Call and recall. Report on a survey of the implementation of cervical cytology call and recall in England and Wales. Birmingham: National Association of Health Authorities, 1988.

5 Elkind A, Eardley A, Thompson R, Smith A. How district health authorities organise cervical screening. Br Med f 1990;301:915-8.

6 Slater DN. Screening of the 1990 contract. Br Med f 1990;300:1034

7 British Society for Clinical Cytology. Recommended code of practice for laboratories providing a cytopathology service. London: British Society for Clinical Cytology, 1986.

8 Histopathology External Quality Assessment Forum. Protocol for an external quality assessment

scheme in cytopathology. London: DHSS, 1987.
Raffle AE, Alden B, Mackenzie EFD. Six years' audit of laboratory workload and rates of referral for colposcopy in a cervical screening programme in three districts. Br Med f 1990;301:907-11. 10 British Medical Association. Cervical cancer and screening in Great Britain. Report. London. BMA, 1986.

11 Intercollegiate Working Party on Cervical Cytology Screening. Report. London: Progress Press, 1987.

12 Evans DMD, Hudson EA, Brown CL, Boddington MM, Hughes HE, MacKenzie EFD. Management of women with abnormal cervical smears: supplement to terminology in gynaecological cytopathology. $\mathcal{F}$ Clin Pathol 1987;40:530-1.

13 Gray JAM, Chamberlain J. Cervical screening management. Lancet 1989;i:280.

\section{Diagnosis and prevention of congenital and perinatal infections}

\section{TORCH screening should be discouraged}

The acronym TORCH was coined in 1971 to draw attention to the need to diagnose congenital infection caused by Toxoplasma gondii, rubella virus, cytomegalovirus, and herpes simplex virus. ${ }^{1}$ Although paediatricians and obstetricians often send serum samples from infants and pregnant women with a request for a TORCH screen, virologists have recently been questioning the value of such requests, which often lead to unnecessary and expensive serological tests. ${ }^{2}$ Moreover, a TORCH screen does not include all congenital and perinatal infections. It does not, for example, include congenital syphilis, although four or five cases occur each year in Britain; parvovirus B19 infection (which causes hydrops fetalis or fetal death in the second trimester in about $9 \%$ of cases when infection occurs in early pregnancy $\left.{ }^{3}\right)$; HIV and varicella zoster virus (which may cause both congenital and perinatal infections $\left.{ }^{4}\right)$; or hepatitis $\mathrm{B}$ virus, human $\mathrm{T}$ cell leukaemia/ lymphoma virus type I, enteroviruses, Chlamydia trachomatis, and several bacteria that can all cause perinatal infections. ${ }^{2}$

A TORCH screen also gives the false impression that all congenital infections can be diagnosed with a single serum sample. Although this may be enough to diagnose congenital rubella and maternal toxoplasmosis and B19 infections, other samples are usually required to diagnose the other infections. Because maternal antibody will complicate the interpretation of specific IgG results and IgM specific for Toxoplasma gondii and cytomegalovirus may be detected in only about half of all congenitally infected neonates, serological results must be interpreted with caution. Kits for TORCH testing using serological methods should therefore be used with care. Congenital cytomegalovirus is best diagnosed in the first three weeks of life by detecting virus in the urine by culture methods, immunofluorescence, or electron microscopy as babies with congenital cytomegalovirus excrete high titres of virus but may have no detectable $\operatorname{IgM}$ specific for cytomegalovirus. Neonatal herpes may be diagnosed similarly, but the features of neonatal herpes may not develop for 10-14 days after birth and about a fifth of infected babies have no skin lesions. ${ }^{5}$ Lesion swabs, cerebrospinal fluid, urine, and throat and eye swabs should all be inoculated into cell cultures. Electron microscopic examination of scrapes from lesions will 
give the most rapid results, but failure to detect virus particles does not exclude infection.

Obstetricians often send requests for TORCH screens on women after an intrauterine death or recurrent abortion. Toxoplasma gondii, rubella, cytomegalovirus, and herpes simplex do not cause recurrent abortion, although they occasionally cause spontaneous abortion if primary infection is acquired in early pregnancy. Listeria monocytogenes, however, may cause intrauterine death, ${ }^{6}$ and parvovirus B19 should be considered if the mother gives a history of a rubellalike illness or contact with a person with rubella-like illness. Testing all patients who have had an intrauterine death for evidence of recent B19 infection is not useful.

Good communication between the local microbiologist and obstetrician or paediatrician is paramount. Requests for specific investigations and the use of rapid diagnostic methods will allow the correct treatment to be started and infected infants isolated if necessary. Lack of communication may lead to a delay in diagnosis and failure to implement infection control policies, resulting in the spread of infection. Enterovirus infections have, for example, closed newborn nurseries. ${ }^{7}$ Delay in investigating urine to diagnose congenital cytomegalovirus infections may result in failure to differentiate these from perinatally acquired infections.

The need to prevent intrauterine and perinatal infections has recently been highlighted in the press. Most perinatal infections with hepatitis $B$ virus can be prevented by giving hepatitis $B$ specific immunoglobulin and hepatitis $B$ vaccine at birth to the infants of mothers positive for hepatitis B surface antigen. ${ }^{8}$ We wonder, however, how many babies of mothers infected with hepatitis B virus are not treated, either because the mothers have not been tested antenatally or because vaccine and immunoglobulin are not available at birth. A recent survey at an inner London hospital showed that only $56 \%$ of antenatal patients positive for hepatitis B surface antigen had been tested for it in $1988 .{ }^{9}$ Similar findings have led to the recommendation in the United States that all pregnant women should be tested for hepatitis B surface antigen. ${ }^{10}$ Should Britain also introduce unselected hepatitis $B$ virus screening for pregnant women, at least in centres where a high percentage of the antenatal population is at risk?

Screening women for cytomegalovirus and toxoplasma infections in pregnancy has also been proposed, with a view to preventing the birth of babies with congenital malformations due to these infections. Four fifths of pregnant women in Britain are, however, susceptible to toxoplasma infection, and screening would require repeated testing throughout pregnancy to identify maternal infection as infection is usually symptomatic. ${ }^{11}$ Additional funding would be required before laboratories could undertake this amount of testing. Such a screening programme is easier in France, where only a fifth of women are susceptible to infection. Like toxoplasmosis, cytomegalovirus infection is usually asymptomatic and primary infection in pregnancy would be identified only by repeated serological testing. Even if primary infections were identified the risk of congenital malformation is small as virus is transmitted to the fetus in only $30-40 \%$ of cases and in only $10 \%$ of these will the fetus be damaged by the virus. ${ }^{12}{ }^{13}$ Termination of infected pregnancies would result in the loss of many normal babies and is not always possible as, in contrast to rubella, congenital malformations may result from infections at any stage of pregnancy.

Human $T$ cell leukaemia/lymphoma virus type $I$, a retrovirus associated with adult $T$ cell leukaemia and tropical spastic paraparesis is found most frequently among Japanese and West Indian people. ${ }^{14}$ One route of transmission that has been shown in Japan is from mother to child in breast milk, and this could be prevented if seropositive mothers did not breast feed. ${ }^{15}$ The prevalence of infection among West Indians in London is only $1-4 \%$, however, and the incidence of both adult $\mathrm{T}$ cell leukaemia and tropical spastic paraparesis is low in Britain. Therefore further seroepidemiological studies and cost benefit analyses are required before antenatal screening programmes for this virus are considered.

Reader in Virology,

JENNIFER M BEST

United Medical and Dental School of Guy's

and St Thomas's Hospitals,

St Thomas's Campus,

London SE1 7EH

Consultant Virologist,

SHEENA SUTHERLAND

Public Health Laboratory,

Dulwich Hospital,

London SE22 8PT

I Nahmias AJ, Walls KW, Stewart JA, Hermann KL, Flynt WJ. The TORCH complex-perinata infections associated with rubella, cytomegalo- and herpes simplex viruses. Pediatr Res 1971;5:372-94.

2 Public Health Laboratory Service. TORCH reassessed. Report of a working party on diagnostic tests for congenital infections. London: PHLS, 1990.

Public Health Laboratory Service Working Party on Fifth Disease. Prospective study of human parvovirus (B19) infection in pregnancy. Br Med f 1990;300:1166-70.

Katz SL, Wilfert CM. Human immunodeficiency virus infection of newborns. $N$ Engl f Med 1989;320:1687-9.

5 Freij BJ, Sever JL. Herpes infection in pregnancy. In: Freij BJ, Sever JL, ed. Infectious complications of pregnancy. Philadelphia: W B Saunders, 1988:203-31. (Clinics in Perinatology 1988:15, No 2.)

6 Spencer JAD. Perinatal listeriosis. Br Med f 1987;295:349.

7 Modlin JF. Perinatal echovirus infection: insights from a literature review of 61 cases of serious infection and 16 outbreaks in nurseries. Rev Infect Dis 1986;8:918-26.

8 Wong VCE, Ip HMH, Reeink HW, et al. Prevention of the HBsAg carrier state in newborn infants of mothers who are chronic carriers of $\mathrm{HBsAg}$ and $\mathrm{HBeAg}$ by administration of hepatitis-B vaccine and hepatitis-B immunoglobulin: double blind randomised placebo-controlled study. Lancet 1984;i:921-6.

9 Banatvala JE, Chrystie IL, Palmer SJ, Kenney A. Retrospective study of HIV, hepatitis B and HTLV-1 infection at a London antenatal clinic. Lancet 1990;335:859-60.

10 Immunisation Practices Advisory Committee. Prevention of perinatal transmission of hepatis B virus: prenatal screening of all pregnant women for hepatitis $\mathrm{B}$ surface antigen. $M M W R$ 1988:37:341-51.

11 Fleck DG. Toxoplasmosis. Why bother to screen? Public Health Laboratory Service Microbiology Digest 1989;6:69-73.

12 Best JM. Congenital cytomegalovirus infection. Br Med f 1987;294:1440-1.

13 Pearl KN, Preece PM, Ades A, Peckham CS. Neurodevelopmental assessment after congenita cytomegalovirus infection. Arch Dis Child 1986;61:323-6.

14 Anonymous. HTLV-1 comes of age [Editorial]. Lancet 1988;i:217-9.

15 Ando Y, Saito K, Nakano S, et al. Bottle feeding can prevent transmission of HTLV-1 from mothers to their babies. F Infect 1989;19:25-9.

\section{Screening with discrimination}

\section{Arguments for a national screening body}

Screening is the identification among apparently healthy people of those at sufficient risk of a specific disorder to warrant diagnostic tests and treatment. To some it has an intuitive appeal because of the potential to make substantial inroads into the burden of disease. Others perceive it as being of little or no benefit; indeed, some argue that screening may harm individuals by prompting unnecessary intervention and increased anxiety in those with positive results while falsely assuring those whose results are negative. Persuasive arguments for both views leave the lay person and health professional confused. But screening is not a single entity, and when each test is weighed separately some will be, found wanting and others found to be of great importance to public health. Such a rational analysis is provided in the recently published book by Holland and Stewart. ${ }^{1}$ The authors deal with both the scientific aspects-establishing efficacy in principle-and the practical aspects-implementation and monitoring.

Establishing efficacy is not straightforward, especially for the common diseases of adult life, such as cancer. In such progressive diseases the principal question is whether identifying people at an earlier stage in the natural history of 